\title{
High Expression of the Chemokine Receptor CCR3 in Human Blood Basophils Role in Activation by Eotaxin, MCP-4, and Other Chemokines
}

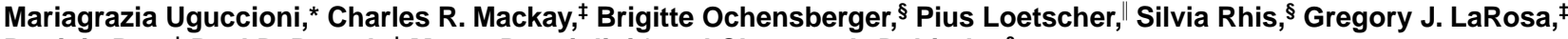 \\ Patricia Rao, ${ }^{\ddagger}$ Paul D. Ponath, ${ }^{\ddagger}$ Marco Baggiolini, ${ }^{*}$ and Clemens A. Dahinden ${ }^{\S}$ \\ *Theodor Kocher Institute, University of Bern, CH-3000 Bern 9, Switzerland; ${ }^{\ddagger}$ LeukoSite, Inc., Cambridge, Massachusetts $02142 ;$ and \\ ${ }^{\S}$ Institute of Immunology and Allergology, "Division of Rheumatology, University Hospital, CH-3010 Bern, Switzerland
}

\begin{abstract}
Eosinophil leukocytes express high numbers of the chemokine receptor CCR3 which binds eotaxin, monocyte chemotactic protein (MCP)-4, and some other CC chemokines. In this paper we show that CCR3 is also highly expressed on human blood basophils, as indicated by Northern blotting and flow cytometry, and mediates mainly chemotaxis. Eotaxin and MCP-4 elicited basophil migration in vitro with similar efficacy as regulated upon activation normal $\mathrm{T}$ cells expressed and secreted (RANTES) and MCP-3. They also induced the release of histamine and leukotrienes in IL-3-primed basophils, but their efficacy was lower than that of MCP-1 and MCP-3, which were the most potent stimuli of exocytosis. Pretreatment of the basophils with a CCR3-blocking antibody abrogated the migration induced by eotaxin, RANTES, and by low to optimal concentrations of MCP-4, but decreased only minimally the response to MCP-3. The CCR3blocking antibody also affected exocytosis: it abrogated histamine and leukotriene release induced by eotaxin, and partially inhibited the response to RANTES and MCP-4. In contrast, the antibody did not affect the responses induced by MCP-1, MCP-3, and macrophage inflammatory protein$1 \alpha$, which may depend on CCR1 and CCR2, two additional receptors detected by Northern blotting with basophil RNA. This study demonstrates that CCR3 is the major receptor for eotaxin, RANTES, and MCP-4 in human basophils, and suggests that basophils and eosinophils, which are the characteristic effector cells of allergic inflammation, depend largely on CCR3 for migration towards different chemokines into inflamed tissues. (J. Clin. Invest. 1997. 100:11371143.) Key words: allergy • inflammation • chemotaxis
\end{abstract}

\section{Introduction}

Chemokines are divided into two main subfamilies according to the position of the first two cysteines which are either separated by one amino acid or adjacent (CXC and CC chemokines) (1). CXC chemokines attract mainly neutrophils and lymphocytes, whereas $\mathrm{CC}$ chemokines are more versatile and

Address correspondence to Dr. Clemens A. Dahinden, Institute of Immunology and Allergology, University Hospital, Inselspital, $\mathrm{CH}-$ 3010 Bern, Switzerland. Phone: 41-31-632-8244; FAX: 41-31-3815735; E-mail: dahinden@insel.ch

Received for publication 13 March 1997 and accepted in revised form 20 May 1997.

J. Clin. Invest.

(C) The American Society for Clinical Investigation, Inc. 0021-9738/97/09/1137/07 \$2.00

Volume 100, Number 5, September 1997, 1137-1143

http://www.jci.org generally activate monocytes, lymphocytes, eosinophils, and basophils (2). All chemokines act via seven transmembrane domain, G protein-coupled receptors (3), and five of them, CCR1-CCR5, are known to mediate responses to CC chemokines. The best-characterized ligands are regulated upon activation normal $\mathrm{T}$ cells expressed and secreted (RANTES), macrophage inflammatory protein (MIP)- $1 \alpha$, and monocyte chemotactic protein (MCP)-3 for CCR1 (4-7), MCP-1 and other MCPs for CCR2 $(6,8,9)$, eotaxin, RANTES, and MCP-3 for CCR3 (10-12), MIP-1 $\alpha$ and RANTES for CCR4 (13), and MIP-1 $\alpha$, MIP-1 $\beta$, and RANTES for CCR5 (14-16). The expression of $\mathrm{CC}$ chemokine receptors differs depending on the type of leukocyte, and influences responsiveness. It is the basis for the selectivity observed in the migration of circulating leukocytes into inflamed tissues in response to chemokines (3).

Since eosinophils and basophils are major effector cells in allergic inflammation (17), we have studied two recently characterized, powerful eosinophil attractants, eotaxin and MCP-4, as potential agonists for basophils. Eotaxin has been reported to be selective for eosinophils (18) and to act via CCR3 (19). MCP-4 has similar properties, but also acts on monocytes and lymphocytes, like other MCPs and RANTES (17, 20-26). In this paper, we show that eotaxin and MCP-4 are powerful stimuli for basophils and induce chemotaxis and the release of histamine and peptido-leukotrienes. These activities are mediated mainly via CCR3, which is highly expressed both in eosinophils and basophils.

\section{Methods}

Chemokines. All chemokines were prepared by automated solidphase chemical synthesis on a peptide synthesizer (430A; Applied Biosystems, Inc., Foster City, CA) using the tertiary butyloxycarbonyl and benzyl protection strategy (27). Recombinant human IL-3 was kindly provided by Sandoz, Ltd. (Basel, Switzerland).

Monoclonal antibodies. The $\mathrm{mAb}$ of $\mathrm{IgG} 2 \mathrm{a}$ isotype 7B11, which blocks CCR3, was generated as previously described (19). An mAb against the $\alpha$ chain of the high-affinity IgE-receptor (anti-Fc $\in \mathrm{RI}$ ) was generously provided by Dr. Hakimi and Dr. Chizzonite (Hoffman-La Roche, Nutley, NJ) (28). FITC-labeled anti-CD9 was purchased from Serotec Ltd. (Kidlington, Oxford, United Kingdom).

Cells. Basophils from venous blood of healthy volunteers (29) were enriched $(10-45 \%)$ by fractionation in a discontinuous Percoll gradient, and further purified by negative selection with magnetic beads coated with mAbs against CD3, CD4, CD8, CD14, CD16, and CD19 (30). The final cell suspension consisted of 70-80\% basophils and $20-30 \%$ lymphocytes. Basophils used for RNA extraction were purified to near homogeneity by an additional positive selection step using FITC-labeled anti-Fc $\in$ RI followed by magnetic beads coated

1. Abbreviations used in this paper: $\mathrm{LTC}_{4}$, leukotriene $\mathrm{C}_{4} ; \mathrm{MCP}$, monocyte chemotactic protein; MIP, macrophage inflammatory protein; RANTES, regulated upon activation normal $\mathrm{T}$ cells expressed and secreted. 
with anti-FITC. Eosinophils ( $>98 \%$ pure) and IL-2-expanded T lymphocytes were obtained as described previously $(25,31)$.

Flow cytometry. Mixtures of basophils and mononuclear cells and of neutrophils and eosinophils were obtained by Percoll gradient centrifugation without negative selection. The cells suspended in PBS supplemented with $10 \%$ FCS and 1 mM EDTA were incubated with anti-CCR3 or isotype-matched control $\mathrm{mAb}$ for $30 \mathrm{~min}$ on ice and then treated with PE-conjugated goat anti-mouse Fab (Southern Biotechnology Associates, Inc., Birmingham, AL). Two-color staining was performed with FITC-labeled anti-Fc $\in$ RI for basophils, and with FITC-labeled anti-CD9 for eosinophils. After fixation, the cells were analyzed by flow cytometry (FACScan ${ }^{\circledR}$, Becton Dickinson, Mountain View, CA). For estimation of anti-CCR3 binding sites, 100 $\mu l$ heparinized blood diluted with $100 \mu$ l PBS containing $0.1 \%$ azide was incubated at room temperature with $400 \mathrm{ng}$ FITC-labeled antiCCR3 and 500 ng biotin-coupled anti-human IgE (PharMingen, San Diego, CA). After washing, the cells were stained by addition of $5 \mu \mathrm{l}$ Streptavidin-Quantum red (Sigma Chemical Co., St. Louis, MO). Erythrocytes were lysed, and the leukocytes analyzed by flow cytometry. Fluorescence was calibrated with Quantum 26 beads (Flow Cytometry Standards Corp., San Juan, Puerto Rico). The mean equivalents of soluble fluorochrome-to-protein ratio for the FITC-labeled anti-CCR3 preparation was determined using Simply Cellular beads (Flow Cytometry Standards Corp.). The mean number of bound antibody molecules per cell was calculated from the median channel fluorescence of the stained cells (19).

Histamine and leukotriene $C_{4}\left(L T C_{4}\right)$ release. Basophils $\left(1-3 \times 10^{5}\right.$ cells $/ \mathrm{ml}$ ) in $20 \mathrm{mM}$ Hepes, $\mathrm{pH} 7.4$, containing $125 \mathrm{mM} \mathrm{NaCl}, 5 \mathrm{mM}$ $\mathrm{KCl}, 1 \mathrm{mM} \mathrm{MgCl}, 1 \mathrm{mM} \mathrm{CaCl}_{2}, 0.5 \mathrm{mM}$ glucose, and $0.025 \% \mathrm{BSA}$ were warmed to $37^{\circ} \mathrm{C}$, exposed to IL-3 $(10 \mathrm{ng} / \mathrm{ml})$ or buffer for $5 \mathrm{~min}$, and then challenged with a chemokine. The reaction was stopped on ice after $20 \mathrm{~min}$, and histamine and $\mathrm{LTC}_{4}$ were measured in the supernatants (32). Histamine release was expressed as percentage of the total cellular content, and $\mathrm{LTC}_{4}$ generation as nanograms per $10^{6}$ basophils. All experiments were repeated at least three times with cells from different donors.

In vitro chemotaxis. In vitro chemotaxis was assessed in 48-well chambers (NeuroProbe, Cabin John, MD) using polyvinylpyrrolidone-free polycarbonate membranes with $5-\mu \mathrm{m}$ pores (Nucleopore; NeuroProbe) (21). RPMI 1640 supplemented with $20 \mathrm{mM}$ Hepes, $\mathrm{pH}$ 7.4, containing $1 \%$ pasteurized plasma protein solution (Central Laboratory of the Swiss Red Cross) was used to dissolve the chemokines and to suspend the cells. After incubation for $60 \mathrm{~min}$ at $37^{\circ} \mathrm{C}$ in $5 \%$ $\mathrm{CO}_{2}$, the membrane was removed, washed with PBS on the upper side, fixed, and stained with May-Grunwald/Giemsa. All assays were done in triplicate, and the basophils migrated across the filter were counted in five randomly selected fields at a magnification of 1,000. Spontaneous migration was determined in the absence of chemoattractant. When indicated, anti-CCR3 (5 or $10 \mu \mathrm{g} / \mathrm{ml}$ ) was added to the cells 10 min before loading into chemotaxis chambers.

Northern blot analysis. Total leukocyte RNA was extracted by the RNAzol B method (Tel-Test, Inc., Friendswood, TX). Samples of 1-5 $\mu \mathrm{g}$ RNA were fractionated on $0.8 \%$ denaturing agarose-formaldehyde gels (33), vacuum-transferred onto Nytran membranes, and immobilized. A 1.3-kbp BamH1 fragment of CCR3 (12), a 360-bp PCR fragment corresponding to an internal region in $\operatorname{CCR} 1(4,5)$, and a 478 bp BstI/ClaI fragment of CCR2 (8) were labeled with $\left[\alpha-{ }^{32} \mathrm{P}\right] \mathrm{dATP}$ using a random primer labeling kit (Boehringer Mannheim, Mannheim, Germany) and used as a hybridization probe at $2 \times 10^{6} \mathrm{cpm} / \mathrm{ml}$ in the presence of $50 \%$ formamide at $42^{\circ} \mathrm{C}$ for $24 \mathrm{~h} \mathrm{(33).} \mathrm{The} \mathrm{mem-}$ brane was washed to a stringency of $0.5 \times \mathrm{SSC}, 0.1 \%$ SDS at $65^{\circ} \mathrm{C}$, and exposed to screens that were then analyzed with a PhosphorImager (Molecular Dynamics, Sunnyvale, CA) using ImageQuant software. After each hybridization, the probe was removed by washing in $50 \%$ formamide, $0.1 \times \mathrm{SSC}, 0.1 \% \mathrm{SDS}$, at $60^{\circ} \mathrm{C}$ for $30 \mathrm{~min}$.

Transfected cells and binding studies. Murine pre-B lymphoma cell lines stably expressing the chemokine receptors CCR3 and CCR2b were established as described previously $(12,34)$. For competition binding studies, the CCR3 transfectants were treated overnight with 2 $\mathrm{mM}$ sodium butyrate before harvesting by centrifugation. The cells $(5 \times$ $10^{5}$ ) were incubated at room temperature for $90 \mathrm{~min}$ with $0.1 \mathrm{nM}$ ${ }^{125}$ I-labeled eotaxin or MCP-1 in $100 \mu$ l binding buffer $(50 \mathrm{mM}$ Hepes, pH 7.2, $1 \mathrm{mM} \mathrm{CaCl}_{2}, 5 \mathrm{mM} \mathrm{MgCl}, 0.5 \% \mathrm{BSA}$, and $0.02 \%$ sodium azide), in the presence of increasing concentrations of unlabeled chemokines. Bound and free tracer were separated by filtration using 96-well GF/B Unifilter plates (Packard, Meriden, CT) presoaked in $0.3 \%$ polyethylenimine. The filters were washed at $4^{\circ} \mathrm{C}$ with $300 \mu \mathrm{l}$ binding buffer supplemented with $0.5 \mathrm{M} \mathrm{NaCl}$ to reduce nonspecific binding. All assays were done in duplicate. $\mathrm{IC}_{50}$ values (concentrations at which binding of the iodinated chemokine was inhibited by $50 \%$ ) were calculated by a three-parameter logistic curve fit using KaleidaGraph software (Synergy Software, Inc., Reading, PA).

\section{Results}

Histamine and leukotriene release. In former studies, we have shown that priming with IL-3, IL-5, and other growth factors enhances basophil responsiveness to stimuli of release and is required for agonist-dependent production of leukotrienes $(35,36)$. In Fig. 1, the effects of eotaxin and MCP-4 are compared with those of MCP-1 and MCP-3, the most potent stimuli of basophil mediator release. Significant histamine release was obtained with all four chemokines in unprimed cells, and priming with IL-3 resulted in a marked enhancement. Eotaxin elicited the weakest response, followed by MCP-4, which was about half as effective as MCP-1 and MCP-3. This order of efficacy was consistent in primed and unprimed cells from seven different donors, despite the well-known individual variability of the release response $(29,36)$. All four chemokines also induced the release of $\mathrm{LTC}_{4}$ after priming with IL-3 in the same order of efficacy. By comparison with the responses to MCP-1 and MCP-3, the effects of eotaxin and MCP-4 were weak to moderate. They were concentration dependent, and a maximum was reached between 30 and $300 \mathrm{nM}$ (Fig. 1).

Chemotaxis. Eotaxin and MCP-4 were potent and effective chemoattractants for basophils. The concentration dependence was typically bimodal, with maximum migration at 10 $\mathrm{nM}$ (Fig. 2). The efficacy of eotaxin and MCP-4 as expressed by the number of migrating cells at optimal concentration was similar to that of MCP-3 and considerably higher than that of MCP-1. It was shown previously that MCP-1 is a weak chemoattractant for basophils despite its high efficacy as stimulus for release (17). The chemotactic activity of eotaxin and MCP-4 obtained for basophils is similar to that formerly reported for eosinophils (21).

Role of CCR3 in the basophil response to chemokines. Several independent studies have shown that eotaxin is a potent and apparently selective ligand for the chemokine receptor CCR3 (10-12). The role of this receptor in basophils was assessed with a blocking antibody (19). As illustrated in Fig. 3, anti-CCR3 abrogated histamine release induced by eotaxin, and decreased the effect of RANTES and, to a lesser extent, of MCP-2, MCP-3, and MCP-4. However, no effect was observed on the release induced by MCP-1, MIP-1 $\alpha$, and IL- 8 . The same pattern of antibody-dependent inhibition was observed for the generation of $\mathrm{LTC}_{4}$ (data not shown). Anti-CCR3 was more effective as inhibitor of chemotaxis. As shown in Fig. 4, migration toward eotaxin and RANTES was virtually abolished. The response to MCP-4 was also markedly inhibited, but the effect decreased with increasing chemokine concentration: inhibition was almost complete at 3 and $10 \mathrm{nM}$ but only marginal 

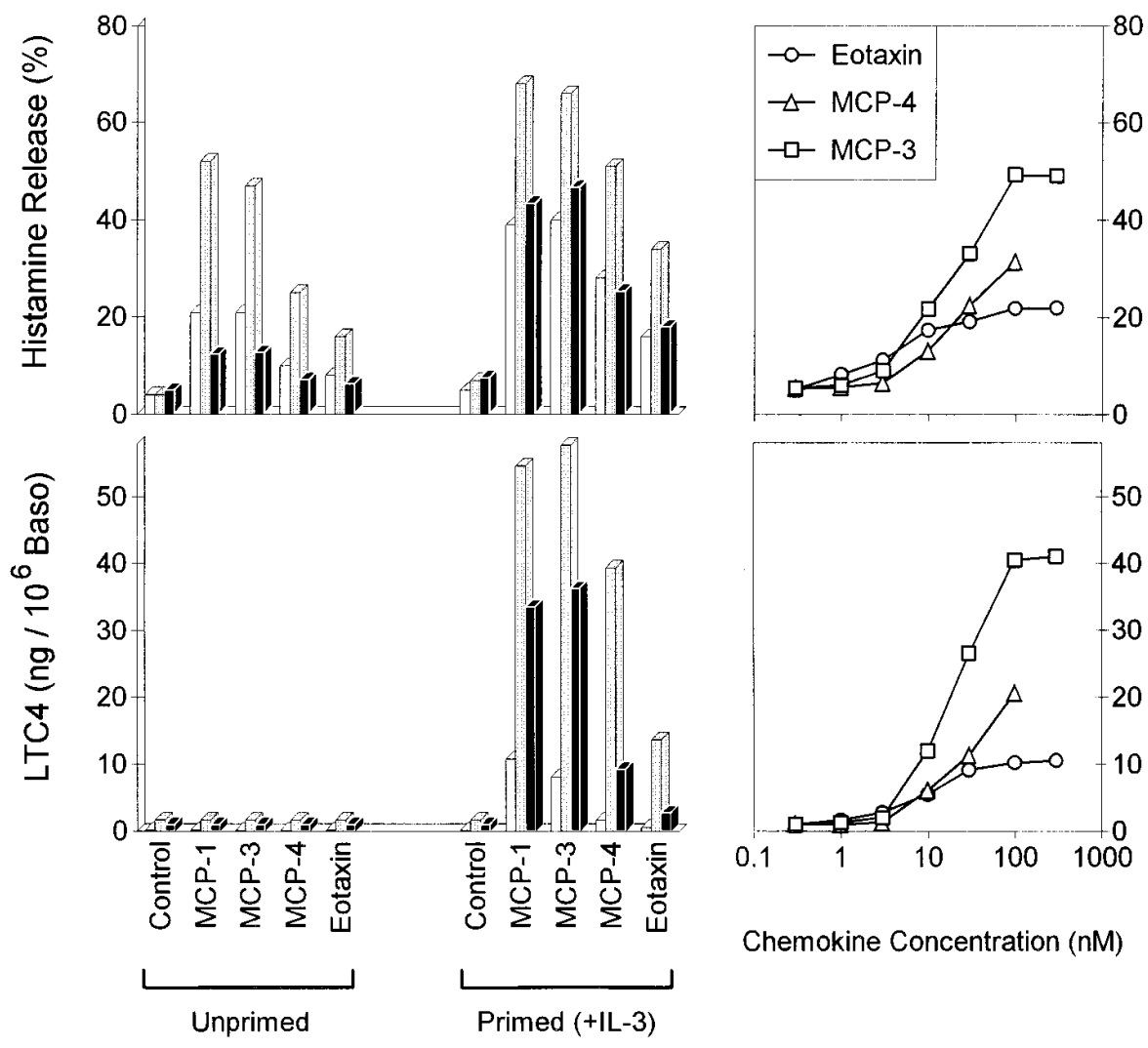

Figure 1. Basophil mediator release. (Left) Chemokine-induced release of histamine (percentage of total cellular content) and generation of $\mathrm{LTC}_{4}\left(\mathrm{ng} / 10^{6}\right.$ basophils) with or without pretreatment with $10 \mathrm{ng} / \mathrm{ml} \mathrm{IL-3} \mathrm{for} 5 \mathrm{~min}$ (primed/unprimed cells). All chemokines were used at 100 $\mathrm{nM}$. Three experiments with cells from different donors are shown in different shadings (means of duplicates). (Right) Concentration dependence of chemokine effects on IL-3-primed basophils. Mean values of three experiments with cells from different donors.

at $100 \mathrm{nM}$. Anti-CCR3, by contrast, affected only minimally the migration induced by MCP-3.

Additional information on the receptors that mediate $\mathrm{LTC}_{4}$ release was obtained by testing the ability of different chemokines to desensitize the basophils toward MCP-1 or eotaxin, which can be regarded as selective ligands for CCR2 and CCR3, respectively. As shown in Table I, the response to MCP-1 was blocked by pretreatment with MCP-1, MCP-2, and $\mathrm{MCP}-3$, in agreement with former studies (37), and also by pretreatment with MCP-4 but not with eotaxin, RANTES, or MIP-1 $\alpha$. The response to eotaxin was abrogated by pretreatment with all chemokines except MCP-1 and MIP-1 $\alpha$. This result is in agreement with the observation that anti-CCR3 did not modify the action of MCP- 1 and MIP- $1 \alpha$, but decreased the release induced by eotaxin, MCP-3, MCP-4, and RANTES.

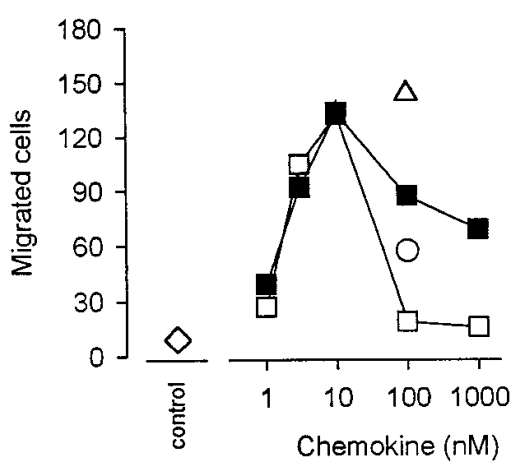

Figure 2. Basophil chemotaxis. In vitro migration (cells per five high-power fields) in response to eotaxin $(\square)$ and MCP-4 (ם). Migration in response to maximally effective concentrations of MCP-1 $(\bigcirc)$ and $\mathrm{MCP}-3(\triangle)$ are shown for comparison. Mean values \pm SEM of three experiments performed with cells from different donors.

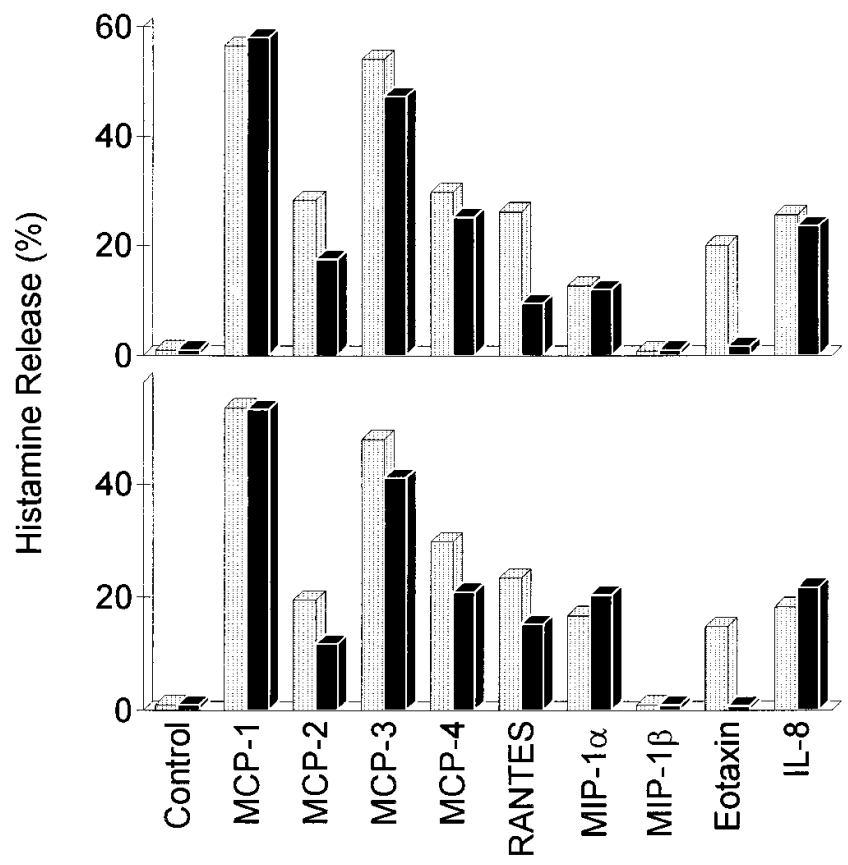

Figure 3. Effect of CCR3-blocking antibody on histamine release. IL-3-primed basophils were left untreated (light columns) or exposed to $5 \mu \mathrm{g} / \mathrm{ml}$ anti-CCR3 for $10 \mathrm{~min}$ (black columns) and then stimulated with a chemokine $(100 \mathrm{nM})$. The response was stopped after $20 \mathrm{~min}$, and histamine was measured in the supernatants. Two experiments performed with cells from different donors are shown. 

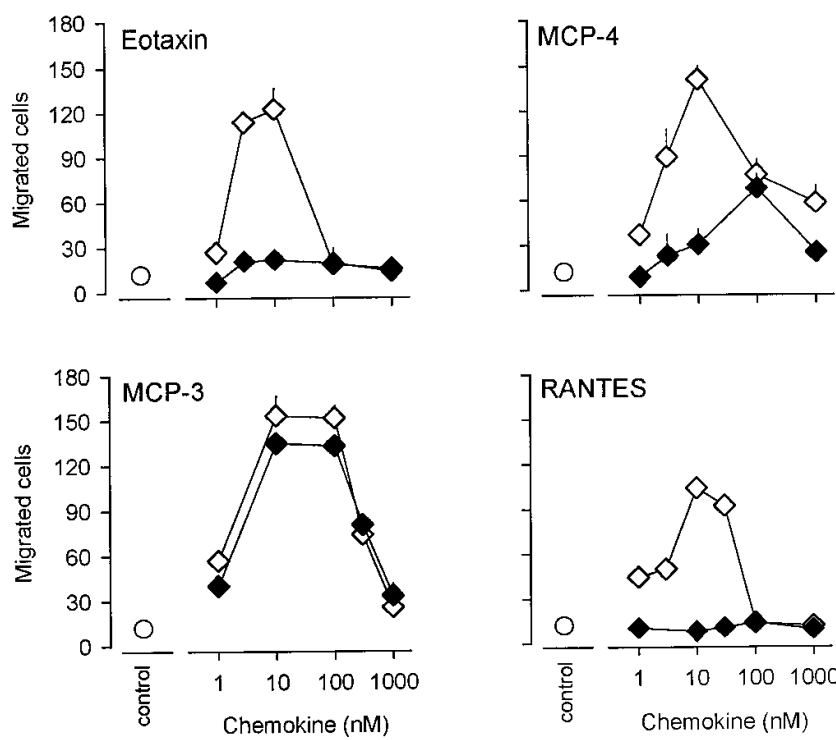

Figure 4. Effect of CCR3-blocking antibody on basophil chemotaxis. In vitro migration (cells per five high-power fields) was assessed in the absence (open symbols) or presence (closed symbols) of $5 \mu \mathrm{g} / \mathrm{ml}$ anti-CCR3. Mean values \pm SEM of three experiments performed with cells from different donors. The SEM is not visible if smaller than the symbols.

Expression of CC chemokine receptors on basophils. Our functional data strongly suggest that CCR3 is expressed on basophils. Using anti-CCR3 and two marker antibodies, anti-FceRI to differentiate basophils from other leukocytes, and anti-CD9 to differentiate eosinophils from neutrophils, the occurrence of CCR3 was assessed by flow cytometry. As shown in Fig. 5 $A$, all FceRI-positive cells, which correspond to the basophils, stained strongly with anti-CCR3. The same was observed for CD9-positive cells, the eosinophils, but not for the CD9-negative neutrophils. Analysis of the gated FceRI-positive cells shows a unimodal anti-CCR3 staining pattern, suggesting that the CCR3 expression on basophils is uniform. Quantitative analysis of the Fc $\in$ RI-positive cells in the unfractionated blood of 30 individuals yielded an average of $19,000 \pm 4,500$ CCR3

Table I. Desensitization of $\mathrm{LTC}_{4}$ Generation in Human Basophils

\begin{tabular}{llc}
\hline & \multicolumn{2}{c}{ Desensitization of the response to: } \\
\cline { 2 - 3 } Preincubation & MCP-1 & Eotaxin \\
\hline MCP-1 & Yes & No \\
MCP-2 & Yes & Yes \\
MCP-3 & Yes & Yes \\
MCP-4 & Yes & Yes \\
Eotaxin & No & Yes \\
RANTES & No & Yes \\
MIP-1 $\alpha$ & No & No
\end{tabular}

Basophils were incubated with different chemokines $(100 \mathrm{nM})$ for $5 \mathrm{~min}$, exposed to IL-3 (10 ng/ml), and subsequently stimulated with MCP-1 or eotaxin $(100 \mathrm{nM}) . \mathrm{LTC}_{4}$ generation was either not affected (No) or completely prevented (Yes).
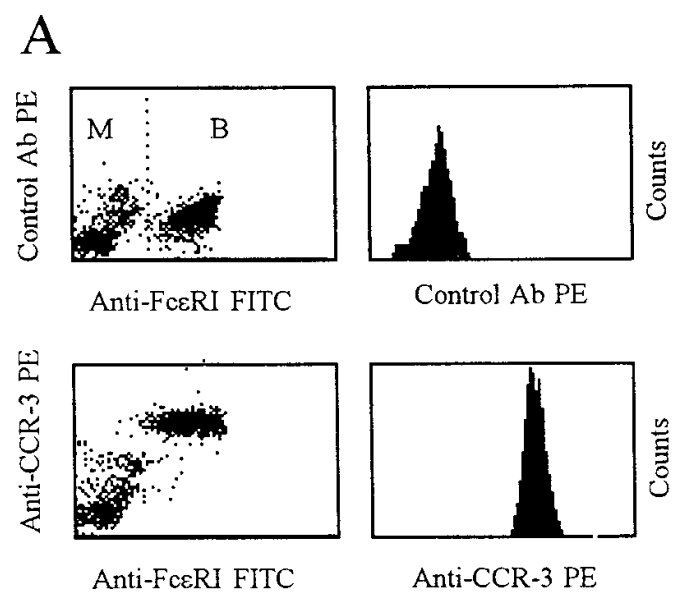

Anti-FceRI FITC

Anti-CCR-3 PE

B

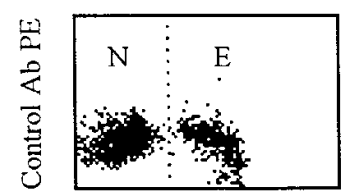

Anti-CD9 FITC

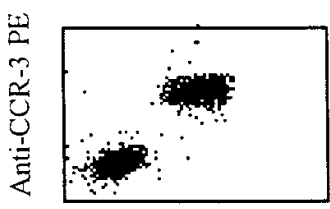

Anti-CD9 FITC

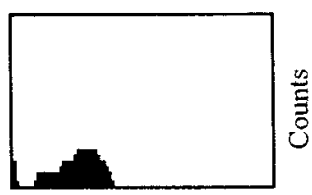

Control Ab PE

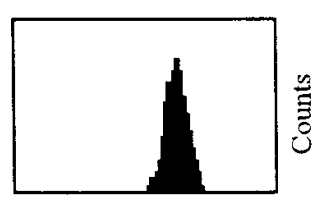

Anti-CCR-3 PE
Figure 5. CCR3 expression of basophils and eosinophils analyzed by flow cytometry. Two-color analysis of a mixture of mononuclear cells $(M)$ and basophils $(B)$, or a mixture of neutrophils $(N)$ and eosinophils $(E)$, is shown in $A$ and $B$, respectively. The cells were incubated with anti-CCR3 $\mathrm{mAb}$ (lower diagrams) or isotype-matched control $\mathrm{mAb}$ (upper diagrams) followed by PE-goat anti-mouse Fab. The basophil-PBMC mixture was then stained with FITC-labeled anti-Fc $\in \mathrm{RI}$ $(A)$, and the neutrophil-eosinophil mixture with FITC-anti-CD9 $(B)$, as specific markers for basophils and eosinophils, respectively. The $\log$ red (PE; vertical axis) versus the log green (FITC; horizontal axis) fluorescence diagrams are shown on the left. The log red $(P E)$ fluorescence of the IgE-receptor-positive-gated basophils $(B)$ and of the CD9-positive-gated eosinophils $(E)$ are shown on the right.

sites per basophil (mean \pm SEM). A similar CCR3 density was observed in eosinophils (Fig. 5). Using an mAb specific for CCR5, a receptor that binds RANTES, MIP- $1 \alpha$, and MIP-1 $\beta$ and functions as an HIV coreceptor (38-40), no CCR5 expression was detectable on basophils (data not shown). This observation is consistent with the lack of activity of MIP-1 $\beta$ on these cells (Fig. 3).

CCR1, CCR2, and CCR3 expression was also determined in highly purified basophils, eosinophils, and IL-2-expanded T lymphocytes by Northern blotting. As shown in Fig. 6, abundant expression of mRNA for CCR3 was found in basophils and eosinophils. Basophils also expressed transcripts for CCR2 and low levels for CCR1, whereas IL-2-expanded lymphocytes were positive for CCR1 and CCR2 but negative for CCR3. Unstimulated blood lymphocytes, the minor contami- 


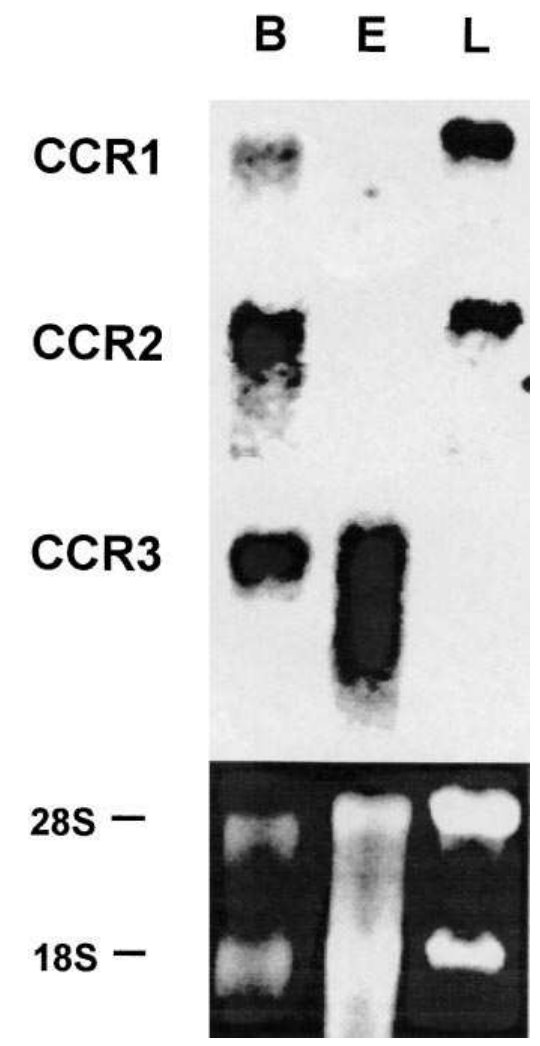

Figure 6. CC chemokine receptor expression. Total RNA from basophils $(1 \mu \mathrm{g}, B)$, eosinophils $(4.5 \mu \mathrm{g}, E)$, and IL-2-expanded T lymphocytes $(5 \mu \mathrm{g}, L)$, was analyzed by Northern blotting. The blot was sequentially hybridized with ${ }^{32} \mathrm{P}$-labeled DNA probes for CCR1, CCR2, and CCR3.

(Bottom) Ethidium bromide-stained RNA in the agarose gel.

nants of the basophil preparations, do not express detectable levels of mRNA for CCR1, CCR2, and CCR3, even if 10 times more RNA is used for blotting (25).

Binding experiments. Our results indicate that CCR3 and CCR2 are the major CC chemokine receptors on basophils, and suggest that CCR3 mainly mediates migration while $\mathrm{CCR} 2$ is involved primarily in histamine and $\mathrm{LTC}_{4}$ release. To assess the affinity of the chemokines for these receptors, competition binding assays were performed using cell lines stably expressing CCR3 or CCR2b, and eotaxin or MCP-1 as the respective labeled ligands. In agreement with former evidence $(21,26)$, competition for binding to CCR3 yielded equally high affinity for eotaxin and MCP-4, and 30-40-fold lower affinity for MCP-3 (Fig. 7 A). MCP-1, MCP-3, and MCP-4 readily competed for binding to $\mathrm{CCR} 2$, but the affinity of MCP-1 was $\sim 10$-fold higher than that of MCP-3 and MCP-4. The Hill coefficient of the displacement curves was $\sim 1$ for MCP-1, and 0.6-0.7 for MCP-3 and MCP-4, in agreement with the difference in slope (Fig. 7 B). IL-8 and MIP- $1 \alpha$ showed no binding to either of these receptors, as expected.

\section{Discussion}

Our results show that human blood basophils express the eotaxin receptor CCR3 and strongly respond to eotaxin, MCP-4, and other chemokines known to attract eosinophils. Flow cytometry counts with FITC-labeled anti-CCR3 show that basophils (these data) and eosinophils (19) bear on average $\sim 20,000$ copies of CCR3. The density of CCR3 thus appears to be considerably higher than that of other CC chemokine receptors on leukocytes (2). In addition to CCR3, basophils were found to express transcripts for CCR1 and CCR2 but not for CCR5.
Essential information about the functional role of CCR3 in basophils was obtained with the blocking antibody. AntiCCR3 abrogated chemotaxis and mediator release in response to eotaxin, which thus appears to be selective for CCR3, as formerly shown for eosinophils $(10-12,18)$. The effect of the antibody indicates that CCR3 is the predominant receptor for basophil migration in response to RANTES and MCP-4 but not to MCP-3. The difference in receptor usage by MCP-3 and MCP-4 can be attributed to the affinities of these ligands to the relevant receptors. As shown by the binding experiments, MCP-4 has a 40-fold higher affinity for CCR3 than MCP-3. It is unclear which receptor may elicit chemotaxis in response to MCP-3. Based on the data obtained with the anti-CCR3 antibody, CCR3 can be excluded. CCR2 is also unlikely, because MCP-1, which is a selective ligand, is a weak basophil attractant (29), and CCR1 or CCR4 are not expected to play a major role, because basophil chemotaxis in response to RANTES, which is a main ligand for both receptors, was shown to depend mainly on CCR3. It may be speculated that MCP-3 acts via a yet unknown receptor or that it triggers a known one more efficiently than other chemokines.

In contrast to chemotaxis, mediator release was less sensitive to anti-CCR3, suggesting the involvement of other receptors. The notion that CCR3 may primarily mediate migration is in agreement with the observation that eotaxin is a much better stimulus of chemotaxis than histamine and leukotriene release. However, the partial antibody-dependent inhibition of histamine release induced by RANTES, MCP-2, MCP-3, and MCP-4 is a clear indication that CCR3 does contribute to the overall effects of $\mathrm{CC}$ chemokines acting via additional recep-
A

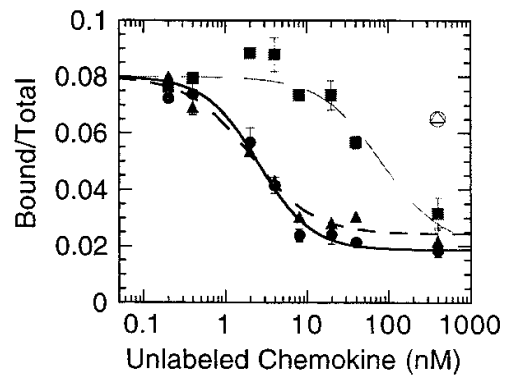

B

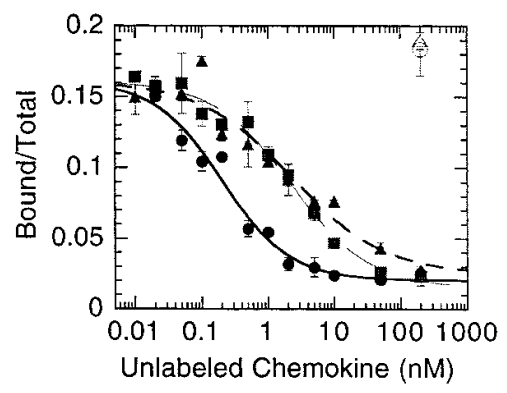

Figure 7. Binding studies with cells expressing CCR 3 or CCR2b. (A) CCR3 transfectants were incubated with $0.1 \mathrm{nM}^{125}$ I-labeled eotaxin in the presence or absence of increasing concentrations of unlabeled eotaxin $(\bullet)$, MCP-3 (ם), or MCP-4 $(\boldsymbol{\Lambda})$. Unlabeled IL-8 $(\triangle)$ or MIP- $1 \alpha(\bigcirc)$ were used at $400 \mathrm{nM}$. The calculated $\mathrm{IC}_{50}$ values (mean \pm SEM) are $2.5 \pm 0.4 \mathrm{nM}$ for eotaxin, $2.0 \pm 0.4 \mathrm{nM}$ for MCP-4, and $80.6 \pm 29 \mathrm{nM}$ for MCP-3. All three competition curves have Hill coefficients of $\sim 1$. (B) CCR2b transfectants were incubated with $0.1 \mathrm{nM}^{125} \mathrm{I}-$ labeled MCP-1 in the presence or absence of

increasing concentrations of unlabeled MCP-1 $(\bullet), \mathrm{MCP}-3(\mathbf{\square})$, or MCP-4 $(\boldsymbol{\Delta})$, or $400 \mathrm{nM}$ unlabeled IL-8 $(\triangle)$ or MIP-1 $\alpha(\bigcirc)$. The calculated $\mathrm{IC}_{50}$ values (mean \pm SEM) are $0.20 \pm 0.04 \mathrm{nM}$ for MCP-1, $2.2 \pm 0.5 \mathrm{nM}$ for MCP-3, and $2.3 \pm 1.4 \mathrm{nM}$ for MCP-4. The Hill coefficient was $\sim 1$ for MCP-1, and 0.6-0.7 for MCP-3 and MCP-4 displacement. 


\begin{tabular}{llllll}
\hline \multicolumn{1}{c}{ Receptors (cells) } & Proposed main function & Known ligands & & & \\
\hline CCR1 (basophils, eosinophils) & Unknown & RANTES & MIP-1 $\alpha$ & MCP-3 & \\
CCR2 (basophils) & Release & MCP-1 & MCP-2 & MCP-3 & MCP-4 \\
CCR3 (basophils, eosinophils) & Chemotaxis & Eotaxin & MCP-2 & MCP-3 & MCP-4 \\
& & & & & \\
\hline
\end{tabular}

tors. Based on the results presented, CCR3 is not involved in the release responses induced by MIP- $1 \alpha$ and MCP-1, which act most likely via CCR1 and CCR2, respectively. It has been shown that MCP-1 is a potent stimulus of exocytosis in basophils (29), and our results indicate that CCR2 is also involved in mediator release elicited by other MCPs. Basophils do not express detectable levels of CCR5 and, accordingly, do not respond to MIP-1 $\beta$. However, they may express CCR4, although we were not able to detect transcripts for this receptor on Northern blots. The functional data argue a minor role for CCR4, because RANTES acts primarily via CCR3, and MIP$1 \alpha$ has only weak activity.

From this study, CCR3 emerges as the major receptor for the recruitment of basophils by three chemokines, eotaxin, MCP-4, and RANTES. It has been pointed out that CCR3 is essential for eosinophil migration and activation by several chemokines $(19,22)$, and it is now interesting to realize that the same applies to the basophil, the other characteristic effector cell of allergic inflammation. In addition to CCR3, which binds eotaxin, RANTES, MCP-2, MCP-3, and MCP-4 but not MCP-1, basophils and eosinophils express CCR1, a receptor for MIP-1 $\alpha$, RANTES, and MCP-3. Basophils also express CCR2, the MCP-1 receptor, which is not found in eosinophils, and binds MCP-2, MCP-3, and MCP-4 as well. Although CCR1 may be expressed in eosinophils of certain individuals (3), the level of transcripts found in basophils is much higher. Today's view of receptor expression and ligand selectivities is presented in Table II, which expands concepts presented in a former review (17).

In light of its prominent role in eosinophil and basophil leukocytes, CCR3 is a promising target for the development of new antiallergic drugs to block selectively the accumulation of the two main effector cells of allergic inflammation. Basophils are the primary source of inflammatory mediators in latephase allergic reactions (17). As shown by more recent studies, however, these cells are also rich sources of IL-4 and IL-13 (41, 42). They may fulfill immunoregulatory functions by contributing to the local differentiation of T lymphocytes towards the Th-2 phenotype (43) and to the stimulation of $\operatorname{IgE}$ production by B lymphocytes (44). Blocking CCR3 may thus also be potentially useful for the treatment of immunopathological conditions that are locally driven by T-helper lymphocytes.

\section{Acknowledgments}

We are grateful to Dr. Beatrice Dewald (Theodor Kocher Institute, University of Bern, Switzerland) for critical reading of the manuscript, and to Dr. Ian Clark-Lewis (Biomedical Research Center, University of British Columbia, Vancouver, Canada) for the supply of chemokines. Donor blood buffy coats were provided by the Swiss Central Laboratory Blood Transfusion Service, Swiss Red Cross.

This work was supported by Swiss National Science Foundation grants 31-41906.94 to C.A. Dahinden, and 31-39744.93 to M. Baggiolini.

\section{References}

1. Baggiolini, M., B. Dewald, and B. Moser. 1994. Interleukin-8 and related chemotactic cytokines-CXC and CC chemokines. Adv. Immunol. 55:97-179.

2. Baggiolini, M., B. Dewald, and B. Moser. 1997. Human chemokines: an update. Annu. Rev. Immunol. 15:675-705.

3. Murphy, P.M. 1996. Chemokine receptors: structure, function and role in microbial pathogenesis. Cytokine Growth Factor Rev. 7:47-64.

4. Neote, K., D. DiGregorio, J.Y. Mak, R. Horuk, and T.J. Schall. 1993. Molecular cloning, functional expression, and signaling characteristics of a $\mathrm{CC}$ chemokine receptor. Cell. 72:415-425.

5. Gao, J.-L., D.B. Kuhns, H.L. Tiffany, D. McDermott, X. Li, U. Francke, and P.M. Murphy. 1993. Structure and functional expression of the human macrophage inflammatory protein 1 $\alpha$ /RANTES receptor. J. Exp. Med. 177:14211427.

6. Combadiere, C., S.K. Ahuja, J. Van Damme, H.L. Tiffany, J.L. Gao, and P.M. Murphy. 1995. Monocyte chemoattractant protein-3 is a functional ligand for CC chemokine receptors 1 and 2B. J. Biol. Chem. 270:29671-29675.

7. Ben-Baruch, A., L.L. Xu, P.R. Young, K. Bengali, J.J. Oppenheim, and J.M. Wang. 1995. Monocyte chemotactic protein-3 (MCP3) interacts with multiple leukocyte receptors. C-C CKR1, a receptor for macrophage inflammatory protein-1 $\alpha /$ Rantes, is also a functional receptor for MCP3. J. Biol. Chem. 270: 22123-22128.

8. Charo, I.F., S.J. Myers, A. Herman, C. Franci, A.J. Connolly, and S.R. Coughlin. 1994. Molecular cloning and functional expression of two monocyte chemoattractant protein 1 receptors reveals alternative splicing of the carboxylterminal tails. Proc. Natl. Acad. Sci. USA. 91:2752-2756.

9. Yamagami, S., H. Tanaka, and N. Endo. 1997. Monocyte chemoattractant protein-2 can exert its effects through the MCP-1 receptor (CC CKR2B). FEBS (Fed. Eur. Biochem. Soc.) Lett. 400:329-332.

10. Kitaura, M., T. Nakajima, T. Imai, S. Harada, C. Combadiere, H.L. Tiffany, P.M. Murphy, and O. Yoshie. 1996. Molecular cloning of human eotaxin, an eosinophil-selective $\mathrm{CC}$ chemokine, and identification of a specific eosinophil eotaxin receptor, CC chemokine receptor 3. J. Biol. Chem. 271:7725-7730.

11. Daugherty, B.L., S.J. Siciliano, J.A. DeMartino, L. Malkowitz, A. Sirotina, and M.S. Springer. 1996. Cloning, expression, and characterization of the human eosinophil eotaxin receptor. J. Exp. Med. 183:2349-2354.

12. Ponath, P.D., S.X. Qin, T.W. Post, J. Wang, L. Wu, N.P. Gerard, W. Newman, C. Gerard, and C.R. Mackay. 1996. Molecular cloning and characterization of a human eotaxin receptor expressed selectively on eosinophils. $J$. Exp. Med. 183:2437-2448.

13. Power, C.A., A. Meyer, K. Nemeth, K.B. Bacon, A.J. Hoogewerf, A.E.I. Proudfoot, and T.N.C. Wells. 1995. Molecular cloning and functional expression of a novel $\mathrm{CC}$ chemokine receptor cDNA from a human basophilic cell line. J. Biol. Chem. 270:19495-19500.

14. Samson, M., O. Labbe, C. Mollereau, G. Vassart, and M. Parmentier. 1996. Molecular cloning and functional expression of a new human CCchemokine receptor gene. Biochemistry. 35:3362-3367.

15. Raport, C.J., J. Gosling, V.L. Schweickart, P.W. Gray, and I.F. Charo. 1996. Molecular cloning and functional characterization of a novel human CC chemokine receptor (CCR5) for RANTES, MIP-1 $\beta$, and MIP-1 $\alpha$. J. Biol. Chem. 271:17161-17166.

16. Combadiere, C., S.K. Ahuja, H.L. Tiffany, and P.M. Murphy. 1996. Cloning and functional expression of CC CKR5, a human monocyte CC chemokine receptor selective for MIP-1 $\alpha$, MIP-1 $\beta$, and RANTES. J. Leukocyte Biol. 60:147-152.

17. Baggiolini, M., and C.A. Dahinden. 1994. CC chemokines in allergic inflammation. Immunol. Today. 15:127-133.

18. Ponath, P.D., S.X. Qin, D.J. Ringler, I. Clark-Lewis, J. Wang, N. Kassam, H. Smith, X.J. Shi, J.A. Gonzalo, W. Newman, et al. 1996. Cloning of the human eosinophil chemoattractant, eotaxin. Expression, receptor binding, and functional properties suggest a mechanism for the selective recruitment of eosinophils. J. Clin. Invest. 97:604-612.

19. Heath, H., S. Quin, P. Rao, L. Wu, G.J. LaRosa, N. Kassam, P.D. Ponath, and C.R. Mackay. 1997. Chemokine receptor usage by human eosinophils. The importance of CCR3 demonstrated using an antagonistic monoclonal antibody. J. Clin. Invest. 99:178-184.

20. Dahinden, C.A., T. Geiser, T. Brunner, V. von Tscharner, D. Caput, P. Ferrara, A. Minty, and M. Baggiolini. 1994. Monocyte chemotactic protein 3 is 
a most effective basophil- and eosinophil-activating chemokine. J. Exp. Med. 179:751-756.

21. Uguccioni, M., P. Loetscher, U. Forssmann, B. Dewald, H.D. Li, S.H. Lima, Y.L. Li, B. Kreider, G. Garotta, M. Thelen, and M. Baggiolini. 1996. Monocyte chemotactic protein 4 (MCP-4), a novel structural and functional analogue of MCP-3 and eotaxin. J. Exp. Med. 183:2379-2384.

22. Baggiolini, M. 1996. Eotaxin: a VIC (very important chemokine) of allergic inflammation? J. Clin. Invest. 97:587.

23. Van Damme, J., P. Proost, J.-P. Lenaerts, and G. Opdenakker. 1992. Structural and functional identification of two human, tumor-derived monocyte chemotactic proteins (MCP-2 and MCP-3) belonging to the chemokine family. J. Exp. Med. 176:59-65.

24. Uguccioni, M., M. D’Apuzzo, M. Loetscher, B. Dewald, and M. Baggiolini. 1995. Actions of the chemotactic cytokines MCP-1, MCP-2, MCP-3, RANTES, MIP-1 $\alpha$ and MIP-1 $\beta$ on human monocytes. Eur. J. Immunol. 25:6468.

25. Loetscher, P., M. Seitz, M. Baggiolini, and B. Moser. 1996. Interleukin-2 regulates $\mathrm{CC}$ chemokine receptor expression and chemotactic responsiveness in T lymphocytes. J. Exp. Med. 184:569-577.

26. Garcia-Zepeda, E.A., C. Combadiere, M.E. Rothenberg, M.N. Sarafi, F. Lavigne, Q. Hamid, P.M. Murphy, and A.D. Luster. 1996. Human monocyte chemoattractant protein (MCP)-4 is a novel CC chemokine with activities on monocytes, eosinophils, and basophils induced in allergic and nonallergic inflammation that signals through the CC chemokine receptors (CCR)-2 and -3 . J. Immunol. 157:5613-5626.

27. Clark-Lewis, I., B. Moser, A. Walz, M. Baggiolini, G.J. Scott, and R. Aebersold. 1991. Chemical synthesis, purification, and characterization of two inflammatory proteins, neutrophil activating peptide 1 (interleukin-8) and neutrophil activating peptide 2. Biochemistry. 30:3128-3135.

28. Riske, F., J. Hakimi, M. Mallamaci, M. Griffin, B. Pilson, N. Tobkes, P. Lin, W. Danho, J. Kochan, and R. Chizzonite. 1991. High affinity human IgE receptor (FceRI). J. Biol. Chem. 266:11245-11251.

29. Bischoff, S.C., M. Krieger, T. Brunner, and C.A. Dahinden. 1992. Monocyte chemotactic protein 1 is a potent activator of human basophils. $J$. Exp. Med. 175:1271-1275.

30. Bischoff, S.C., M. Krieger, T. Brunner, A. Rot, V. von Tscharner, M. Baggiolini, and C.A. Dahinden. 1993. RANTES and related chemokines activate human basophil granulocytes through different $\mathrm{G}$ protein-coupled receptors. Eur. J. Immunol. 23:761-767.

31. Rot, A., M. Krieger, T. Brunner, S.C. Bischoff, T.J. Schall, and C.A. Dahinden. 1992. RANTES and macrophage inflammatory protein $1 \alpha$ induce the migration and activation of normal human eosinophil granulocytes. J. Exp. Med. 176:1489-1495.
32. Bischoff, S.C., and C.A. Dahinden. 1992. Effect of nerve growth factor on the release of inflammatory mediators by mature human basophils. Blood. 79:2662-2669.

33. Sambrook, J., E.F. Fritsch, and T. Maniatis. 1989. Molecular Cloning: A Laboratory Manual. Cold Spring Harbor Laboratory, Cold Spring Harbor, NY.

34. Qin, S.X., G. LaRosa, J.J. Campbell, H. Smith-Heath, N. Kassam, X.J. Shi, L. Zeng, E.C. Butcher, and C.R. Mackay. 1996. Expression of monocyte chemoattractant protein-1 and interleukin-8 receptors on subsets of T cells: correlation with transendothelial chemotactic potential. Eur. J. Immunol. 26:640647

35. Takafuji, S., S.C. Bischoff, A.L. De Weck, and C.A. Dahinden. 1991. IL-3 and IL-5 prime normal human eosinophils to produce leukotriene C4 in response to soluble agonists. J. Immunol. 147:3855-3861.

36. Bischoff, S.C., T. Brunner, A.L. De Weck, and C.A. Dahinden. 1990. Interleukin 5 modifies histamine release and leukotriene generation by human basophils in response to diverse agonists. J. Exp. Med. 172:1577-1582.

37. Weber, M., M. Uguccioni, B. Ochensberger, M. Baggiolini, I. ClarkLewis, and C.A. Dahinden. 1995. Monocyte chemotactic protein MCP-2 activates human basophil and eosinophil leukocytes similar to MCP-3. J. Immunol. 154:4166-4172.

38. Alkhatib, G., C. Combadiere, C.C. Broder, Y. Feng, P.E. Kennedy, P.M. Murphy, and E.A. Berger. 1996. CC CKR5: a RANTES, MIP-1 $\alpha$, MIP-1 $\beta$ receptor as a fusion cofactor for macrophage-tropic HIV-1. Science (Wash DC). 272:1955-1958

39. Choe, H., M. Farzan, Y. Sun, N. Sullivan, B. Rollins, P.D. Ponath, L.J. Wu, C.R. Mackay, G. LaRosa, W. Newman, et al. 1996. The $\beta$-chemokine receptors CCR3 and CCR5 facilitate infection by primary HIV-1 isolates. Cell. 85:1135-1148.

40. Doranz, B.J., J. Rucker, Y.J. Yi, R.J. Smyth, M. Samson, S.C. Peiper, M. Parmentier, R.G. Collman, and R.W. Doms. 1996. A dual-tropic primary HIV-1 isolate that uses fusin and the $\beta$-chemokine receptors CKR-5, CKR-3, and CKR-2b as fusion cofactors. Cell. 85:1149-1158.

41. Brunner, T., C.H. Heusser, and C.A. Dahinden. 1993. Human peripheral blood basophils primed by interleukin 3 (IL-3) produce IL-4 in response to immunoglobulin E receptor stimulation. J. Exp. Med. 177:605-611.

42. Ochensberger, B., G.C. Daepp, S. Rihs, and C.A. Dahinden. 1996. Human blood basophils produce interleukin-13 in response to IgE-receptor-dependent and -independent activation. Blood. 88:3028-3037.

43. Seder, R.A., and W.E. Paul. 1994. Acquisition of lymphokine-producing phenotype by $\mathrm{CD}^{+}$T cells. Annu. Rev. Immunol. 12:635-673.

44. Gauchat, J.-F., S. Henchoz, D. Fattah, G. Mazzei, J.-P. Aubry, T. Jomotte, L. Dash, K. Page, R. Solari, D. Aldebert, et al. 1995. CD40 ligand is functionally expressed on human eosinophils. Eur. J. Immunol. 25:863-865. 